\title{
Análise da produção científica internacional em contabilidade aplicada ao setor do agronegócio
}

\section{An analysis of the international scientific production in accounting applied to the agribusiness sector}

\author{
Gabriel Oliveira Loiola Benigno ${ }^{1}$, Matheus Henrique Bastos Leite ${ }^{1}$, \\ Monique Christine Batista de Souza ${ }^{2}$, Ducineli Régis Botelho ${ }^{3}$
}

\begin{abstract}
Resumo
O objetivo da pesquisa é analisar o perfil da produção científica em contabilidade aplicada ao setor do agronegócio, à luz da Lei de Lotka. Foram coletados trabalhos em cinco bases de dados: Emerald, Scopus, Web of Science, SciELO e ScienceDirect. No total de 106 documentos coletados, foram analisados: i) quantidade de trabalhos produzidos por autor; ii) vínculo institucional dos autores; iii) tipo de documento produzido; e iv) temas abordados em subáreas pré-definidas. Concluiu-se que a produção científica na área tem crescido nos últimos 10 anos (2007-2017), principalmente em temas que permeiam a discussão acerca dos ativos biológicos e custos do agronegócio. As revistas científicas identificadas com o maior número de contribuições foram Custos e Agronegócio On line, Agricultural Finance Review e Agribusiness, sendo que o periódico brasileiro apresentou uma maior quantidade de produção científica, destacando, assim, a importância que o País, de caráter exportador, tem frente ao setor de agronegócios. Entretanto, os autores mais prolíficos destacados não são brasileiros; o fato pode ser evidenciado pela escassez da quantidade de produção de autores brasileiros que publicam várias vezes no tema ou poucos autores brasileiros publicam em inglês. Sobre a produtividade dos autores, a máxima de Lotka (1926) pôde ser observada; entretanto, quando analisado o método empírico de ajustamento ao inverso quadrado proposto por Pao (1985), os coeficientes que representam a relação de produtividade dos autores distanciaram-se da Lei de Lotka. A relação estatística foi verificada através do teste Kolmogorov-Smirnov (K-S); os resultados desta pesquisa apontam a aceitação da hipótese nula a 0,01 de nível de significância. Para aceitação da hipótese alternativa, o $\mathrm{D}_{\text {máx }}$ deveria ser menor que o valor crítico, porém, a especificidade da temática, com a presença de poucos artigos na área, aumenta o valor crítico, resultando na rejeição da mesma.
\end{abstract}

Palavras-chave: Bibliometria. Lei de Lotka. Produção científica. Agronegócios. Produtividade.

\footnotetext{
${ }^{1}$ Mestrando no Programa de Pós-graduação em Administração da Universidade de Brasília (UnB), Brasília, Distrito Federal, Brasil.

${ }^{2}$ Graduação em Administração pela Universidade de Brasília, Brasília, Distrito Federal, Brasil.

${ }^{3}$ Doutorado em Ciências Contábeis pelo Programa Multi-institucional e Inter-regional de Pós-graduação em Ciências Contábeis da UnB, UFPB e UFRN, Brasil. Professora do Departamento de Ciências Contábeis e Atuariais da Universidade de Brasília, Brasília, Distrito Federal, Brasil. E-mail: ducineli@unb.br
} 


\begin{abstract}
The objective of this research is to analyze the profile of the scientific production in accounting applied to the agribusiness' sector, in light of the Law of Lotka. The data were collected in five databases: Emerald, Scopus, Web of Science, SciELO and ScienceDirect. A total of 106 documents were analyzed in: i) quantity of works were produced by author; ii) institutional link of authors; iii) type of document produced; and iv) topics covered in pre-defined subareas. It was concluded that the scientific production in this area has grown in the last 10 years (2007-2017), mainly in topics that permeate the discussion about biological assets and agribusiness costs. The scientific journals identified with the largest number of contributions were Costs and Agribusiness On line, Agricultural Finance Review and Agribusiness, and the Brazilian newspaper presented a larger amount of scientific production, highlighting the importance of the exporting country has in relation to the agribusiness sector. However, the most prolific outstanding authors are not Brazilian, the fact can be evidenced by the scarcity of the quantity of production of Brazilian authors who publish several times in the subject or few Brazilian authors publish in English language. On the productivity of the authors, Lotka's maxim (1926) could be observed, however, when analyzing the empirical method of squared inversion proposed by Pao (1985), the coefficients that represent the productivity relationship of the authors distanced themselves from the Lotka's Law. The statistical relationship was verified through the Kolmogorov-Smirnov (K-S) test, the results of this research point out the acceptance of the null hypothesis at 0.01 level of significance. For acceptance of the alternative hypothesis, the $\mathrm{D}_{\max }$ should be less than the critical value, but the specificity of the subject, with the presence of few articles in the area, increases the critical value, resulting in rejection of the alternative hypothesis.
\end{abstract}

Keywords: Bibliometrics. Lotka's Law. Scientific production. Agribusiness. Productivity.

\section{Introdução}

No período de alta inflação, na década de 1990, a agricultura no Brasil enfrentava um grande problema que impedia seu processo de crescimento: seus compromissos financeiros eram atrelados à taxa de inflação (pela correção monetária), mas sua receita era dada pelos preços de seus produtos, que não acompanhavam necessariamente a taxa de inflação (GASQUES et al., 2004).

Atualmente no Brasil, o agronegócio é uma das áreas que mais cresce e, consequentemente, tem cada vez mais impacto na economia nacional.
Figueiredo, Santos e Lima (2012) realizaram estudo no qual verificam o grau de importância do agronegócio na geração de renda no Brasil e nos EUA, comparando a participação do agronegócio ao Produto Interno Bruto (PIB) e com a participação de outros setores que compõem o PIB total desses países, constatando, então, que o setor gera crescimento econômico em ambos os países, porém com maior impacto na economia brasileira.

Nos últimos anos, o percentual da participação do agronegócio no PIB brasileiro se torna cada vez mais significativo, como mostra a Tabela 1.

Tabela 1 - Participação do agronegócio no PIB do Brasil (em \%).

\begin{tabular}{lcccccccc}
\hline Ano / Agronegócio total (A+B+C+D) & 2011 & 2012 & 2013 & 2014 & 2015 & 2016 & 2017 & 2018 \\
\cline { 2 - 8 } & 21,03 & 19,41 & 19,17 & 19,06 & 20,54 & 22,84 & 21,43 & 21,12 \\
\hline A. Insumos & 0,97 & 0,98 & 0,98 & 0,95 & 0,96 & 1,01 & 0,93 & 1,04 \\
B. Agropecuária & 5,39 & 4,71 & 4,75 & 4,70 & 4,89 & 5,71 & 5,31 & 5,15 \\
C. Indústria & 6,21 & 5,91 & 5,72 & 5,66 & 6,09 & 6,60 & 6,26 & 6,26 \\
D. Serviços & 8,46 & 7,81 & 7,71 & 7,75 & 8,60 & 9,53 & 8,93 & 8,67 \\
\hline
\end{tabular}

Fonte: Universidade de São Paulo (2018) 
A Tabela 1 apresenta a participação percentual do setor de agronegócio num panorama geral, abrangendo em "agronegócio total" subdivisões entre os ramos "agrícola" e "pecuário".

Para Jank, Nassar e Tachinradi (2005), o agronegócio é uma das mais importantes fontes geradoras de riqueza do Brasil. A importância desse setor para a economia nacional pode ser medida por indicadores como mão-de-obra empregada, correspondente a $35 \%$ da população economicamente ativa e uma participação de $42 \%$ nas exportações brasileiras. Afirmam ainda que, tamanha importância do setor para a economia brasileira que coloca o País como uma das nações mais competitivas do mundo na produção de commodities.

Silva, Cesário e Cavalcanti (2006) afirmam que o agronegócio brasileiro é moderno, eficiente, competitivo e uma atividade próspera, segura e rentável. Por se tratar de um país de clima diversificado, chuvas regulares, energia solar abundante e quase $13 \%$ de toda a água doce disponível no planeta, o Brasil tem 388 milhões de hectares de terras agricultáveis, férteis e de alta produtividade. Esses fatores fazem do País um lugar naturalmente propício para a agropecuária. Diante dessa perspectiva do agronegócio brasileiro ter uma importância significativa para a economia brasileira, fazem-se necessárias pesquisas que enfoquem esse setor. Para Teixeira (2003), o desafio que se coloca aos pesquisadores das Ciências Sociais Aplicadas é de construir conhecimento científico, numa perspectiva que reconheça e privilegie as características inerentes a essas ciências. A atividade básica da ciência é a pesquisa e seu objetivo fundamental é descobrir respostas para problemas, mediante o emprego de distintos procedimentos metodológicos.

Para determinar o perfil da produção científica em determinada área de estudo é necessário pesquisar trabalhos publicados, para assim, traçar um mapeamento de seus diversos aspectos. A bibliometria, como área de estudo da Ciência da Informação, tem um papel relevante na análise de produção científica, uma vez que seus indicadores retratam o grau de desenvolvimento de uma área do conhecimento de um campo científico ou do saber (ARAÚJO; ALVARENGA, 2011).

Diante do contexto, o estudo se propõe a investigar: "qual é o perfil da produção científica internacional em contabilidade aplicada ao setor de agronegócios?".

Para tanto, esta pesquisa tem o objetivo de analisar o perfil da produção científica em contabilidade aplicada ao setor do agronegócio, à luz da Lei de Lotka. Para isto, este estudo coletou, utilizando-se de técnica bibliométrica, artigos científicos em cinco bases de dados: Emerald, Scopus, Web of Science, SciELO e ScienceDirect.

Com base nos escritos de Pao (1985) e Leite Filho (2008), foi possível estabelecer hipóteses a serem testadas estatisticamente para avaliar a adequação do conjunto de dados reunidos neste trabalho à pesquisa de Lotka, sendo elas:

$H_{0}$ : o conjunto de dados observados está em conformidade com a Lei de Lotka.

$H_{1}$ : o conjunto de dados observados não está em conformidade com a Lei de Lotka.

A importância desta pesquisa para o meio acadêmico é caracterizada, principalmente, pelo delineamento do perfil dos autores que produzem pesquisas relacionadas à contabilidade aplicada ao setor do agronegócio em âmbito internacional, identificando os mais produtivos na área, a rede colaborativa, as universidades que mais contribuem, as principais fontes dos trabalhos, suas subáreas e, por fim, a aplicabilidade ou não da Lei de Lotka à área de estudo.

\section{Referencial Teórico}

\section{Principais aspectos das leis bibliométricas}

Informações sobre o perfil de publicações científicas de determinado segmento ou uma área de interesse são fundamentais para a elaboração de um novo trabalho, pois podem determinar, por exemplo, o assunto a ser explorado ou a metodologia mais adequada. A busca por mais sistematização dos estudos sobre a produção 
científica culminou com o desenvolvimento da bibliometria, técnica que utiliza a matemática e a estatística para descrever os pormenores do que se tem produzido na academia em determinado assunto (ARAÚJO, 2006). Segundo Ribeiro e Silva (2016), os estudos bibliométricos utilizam metodologias para identificar tendências editoriais, coletar conhecimentos sobre determinado tema e apontar lacunas para pesquisas futuras.

Para Guedes e Borschiver (2005), a área da bibliometria é composta por um conjunto de leis e princípios empíricos que contribuem para o estabelecimento da fundamentação teórica. No que se refere às leis bibliométricas, Vanti (2002) e Araújo (2006) entram em consenso quanto às três leis bibliométricas mais reconhecidas na academia, sendo elas:

- Lei de Bradford ou Lei de Dispersão: define-se um núcleo de publicações focadas em um determinado tema e zonas de dispersão identificadas como trabalhos de outras áreas temáticas que se relacionam com o tema central;

- Lei de Zipf ou Lei do Mínimo Esforço: indica a frequência das palavras em trabalhos sobre determinado assunto, ordenando-as da maior para a menor e definindo um grupo de termos mais utilizados;

- Lei de Lotka ou Lei do Quadrado Inverso: mede a produtividade dos autores de acordo com um modelo construído empiricamente, no qual muitos autores publicam poucos trabalhos sobre dada temática, enquanto poucos autores são responsáveis pela maior parte das contribuições científicas.

De acordo com Pao (1985), a Lei de Lotka pode ser descrita por meio de uma fórmula matemática:

$$
x^{n} \cdot y_{x}=c
$$

De acordo com a Equação 1, y é o número de autores que publicaram $x$ contribuições científicas para o assunto estudado, enquanto $\mathrm{n}$ e c são variáveis que se modificam de acordo com o conjunto de dados em questão. Em seu trabalho original de 1926, "The frequency distribution of scientific productivity", Lotka analisou dados do periódico Chemichal Abstract de 1907 a 1916 e do segmento de física da Auerbach, no qual plotou a frequência de contribuições dos autores pelo número de contribuições e se utilizou do Método dos Mínimos Quadrados para calcular a inclinação da reta, valor n na Equação 1, que melhor se ajusta ao seu conjunto de dados. O resultado obtido foi uma inclinação negativa de 2. Para o caso em que n é igual a 2, Lotka (1926) encontrou 0,6079 como $\mathrm{o}$ valor de $\mathrm{c}$, referente à porcentagem de autores com apenas uma contribuição. Valores próximos ao encontrado por Lotka (1926) significam uma maior possibilidade de o conjunto de dados se adequar à Lei do Quadrado Inverso, entretanto, somente um teste estatístico pode confirmar ou rejeitar esta adequação. Leite Filho (2008) enfatiza o teste de Kolmogorov-Smirnov (K-S) para contornar a falta de verificação comum entre os trabalhos bibliográficos.

Aproximando-se dos postulados de Lotka, Quesada et al. (2010) afirmam que a comunidade científica estabelece suas relações conforme modelos de rede social, ou seja, a rede social representa indivíduos, instituições, disciplinas científicas e é ligada por conhecimentos trocados entre pesquisadores no campo científico. Para Bourdieu (1983), pode-se considerar o campo científico como um espaço simbólico e estruturado onde os agentes produzem, reproduzem e difundem o conhecimento científico que é submetido a uma espécie de controle organizacional por pares concorrentes de modo a estruturar o sistema reputacional dos campos científicos; sendo assim, a aquisição de capital científico assegura o poder sobre os mecanismos constitutivos do campo. Os maiores detentores de capital científico seriam então os "pesquisadores dominantes", ou seja, pesquisadores que conseguem impor uma definição de ciência. São esses pesquisadores que, de certa forma, determinam os objetos importantes e aqueles que deverão ser pesquisados por todos os membros do campo (BOURDIEU, 1983 apud CAFÉ et al., 2011). 
Dentro da literatura bibliométrica, destacam-se três formas de contagem de autores: a contagem direta, na qual considera-se apenas os autores principais de cada trabalho, a contagem completa, que também leva em consideração os autores secundários, atribuindo um valor unitário para cada contribuinte, e a contagem ajustada, caracterizada pela distribuição de frações de contribuição igualitárias entre os autores (URBIZAGASTEGUI, 2008).

Goodman (1954) já afirmava, em meados do século XX, que o teste K-S se tornara o padrão para experimentos estatísticos não paramétricos, pois era mais preciso que testes concorrentes. Agora no século XXI, o mesmo teste ainda é usado, como demonstra Leite Filho (2008), para confrontar diferentes séries de dados aos analisados por Lotka (1926), verificando a aderência de tais conjuntos à Lei de Lotka.

O modelo proposto por Lotka (1926) tem sofrido um grande número de críticas desde sua concepção, principalmente em relação a desvios encontrados ao se aplicar seus fundamentos em outras áreas de estudo (URBIZAGASTEGUI, 2008). Ao perceber uma tendência entre os autores a simplesmente aceitar as definições de Lotka, que são aproximações feitas a partir das análises de duas séries de dados pela maior facilidade em se trabalhar com tais valores, Pao (1985) propôs uma metodologia de teste para enquadramento na Lei de Lotka. Esta metodologia calcula o valor das variáveis, de acordo com um método que se aproxima ao máximo do original de 1926, e se realiza o teste estatístico de Kolmogorov-Smirnov para conformidade.

\section{Pesquisas bibliométricas na contabilidade}

Merigó e Yang (2017) identificaram as características bibliométricas sobre a pesquisa em contabilidade por meio da base de dados Web of Science. Foi constatado que as revistas Journal of Accounting \& Economics, The Journal of Accounting Research, The Accounting Review, Accounting e Organizations and Society são as mais influentes, analisadas com base no número de citações recebidas pelos trabalhos científicos publicados. Diferentemente de outras áreas correlatas, nas quais muitos trabalhos recebem mais que 1.000 citações, em contabilidade somente quatro artigos receberam mais que 500. Os autores também constataram que alguns autores influentes não publicam muitos trabalhos ou não recebem muitas citações por tópicos específicos.

Danielson e Heck (2010) realizaram um estudo sobre os autores mais prolíficos nas revistas de contabilidade de alto impacto. Ficou constatado que as revistas do segundo nível tendem a ser dominadas pelos mesmos autores das revistas do primeiro nível, ou seja, publicar no segundo nível pode ser tão difícil quanto no primeiro. Além disso, constatou-se que o autor médio tem apenas 2.652 publicações em um período de pesquisa de 40 anos e que há dispersão no número de autores, com poucos produzindo muito, pois apenas $4,7 \%$ dos autores possuem 10 ou mais aparições, mas que este pequeno conjunto de autores representam 29,1\% de todas as aparições nas 15 revistas estudadas.

Souza et al. (2012) realizaram uma pesquisa similar aplicada aos trabalhos científicos brasileiros, analisando o perfil dos artigos sobre agronegócio publicados nos periódicos de contabilidade com estrato CAPES no período de 2006 a 2011. De 1.665 artigos analisados, foram encontrados 27 relacionados ao tema, sendo a revista Contextus a que mais publicou na temática. Sobre os autores, constataram a não concentração por artigo, pois a maioria $(74,08 \%)$ ficou entre um e três autores, além disso, os dados sugeriram que muitos publicaram poucos estudos nas revistas pesquisadas.

\section{Procedimentos Metodológicos}

Este trabalho se utilizou de técnica bibliométrica com o objetivo de identificar o perfil da produção científica em contabilidade aplicada ao setor do agronegócio, à luz da Lei de Lotka. A coleta de dados da pesquisa engloba cinco bases de 
dados: Emerald, Scopus, Web of Science, SciELO e ScienceDirect. A escolha por pesquisa em bases de dados se justifica pela maior abrangência de temas, áreas e periódicos que possibilitem uma melhor coleta de documentos e por estas se tratarem de plataformas multidisciplinares de alto impacto e grande utilização neste campo de pesquisa. Todas as bases utilizadas foram acessadas a partir do Portal de Periódicos CAPES, no período de outubro de 2017 a janeiro de 2018.

Destaca-se que a base de dados Web of Science não inclui muitos periódicos científicos de contabilidade, em contrapartida o processo de busca é muito bom, visto a qualidade dos periódicos indexados.

A coleta de dados realizada, mediante pesquisa documental, ocorreu pela busca de palavras-chave da área de interesse, de acordo com a especificidade de cada base. Os termos pesquisados foram: accounting, agribusiness, biological assets, family farming, agricultural accounting, costs, historical costs e fair value. Em todas as buscas considerou-se que os termos estivessem contidos no título, no resumo ou nas palavras-chave do próprio trabalho, sem delimitação de recorte temporal.

Após realizadas as pesquisas, feitas as combinações necessárias e aplicados os devidos filtros, obteve-se um retorno total de 1.200 trabalhos não limitados à data de publicação ou tipo de documento. Finalizada a busca por termos, realizou-se análise de título e resumo de cada trabalho encontrado, a fim de verificar a relação de cada um com a área de interesse da pesquisa.

Foram eliminados da busca trabalhos não relacionados à principal área de interesse e trabalhos porventura duplicados, por estarem contidos em bases diferentes, obtendo-se uma amostra final de 106 documentos, dentre eles: artigos de periódicos, capítulos de livros, anais de conferências e congressos.

Os trabalhos selecionados foram coletados e armazenados com o auxílio do software Mendeley ${ }^{\circledR}$, a partir daí iniciou-se a análise. Com o auxílio do software Microsoft Excel ${ }^{\circledR}$, foram produzidas métricas sobre (1) a quantidade de trabalhos produzidos por autor, (2) a instituição de ensino superior na qual cada autor estivera vinculado, (3) o tipo de documento produzido e (4) segregação dos temas abordados em subáreas definidas por elaboração própria (regulamentação; avaliação, evidenciação e mensuração; social disclosure; contabilidade gerencial; contabilidade socioambiental e mercado financeiro e arbitragem). A metodologia proposta por Pao (1985), que inclui o teste estatístico de Kolmogorov-Smirnov (K-S) para conformidade, foi utilizada a fim de se testar a conformidade do conjunto de dados contido neste trabalho à Lei de Lotka. $\mathrm{O}$ cálculo do teste foi obtido a partir da ferramenta Excel $^{\circledR}$. O teste K-S, realizado a 0,01 nível de significância, leva em consideração as seguintes hipóteses:

$H_{0}$ : o conjunto de dados observados está em conformidade com a Lei de Lotka.

$H_{1}$ : o conjunto de dados observados não está em conformidade com a Lei de Lotka.

\section{Resultados, Análises e Discussão}

\section{Análise da amostra}

A amostra revela uma evolução da produção científica relacionada à área de interesse do estudo no período compreendido entre 1990 e 2017 . Com a análise da produção anual distribuídas na linha do tempo, apresentada na Figura 1, é possível observar que a produção de trabalhos relacionados à área de contabilidade aplicada ao setor do agronegócio cresce gradativamente com o passar dos anos, tendo observado um decréscimo mais acentuado entre os anos de 2016 e 2017. Observa-se também que 97 trabalhos, cerca de $90,6 \%$ da amostra, foram produzidos nos últimos 10 anos (2007-2017). Para Souza et al. (2012), o agronegócio brasileiro tem se tornado um campo promissor para as pesquisas científicas, uma vez que é notável seu crescimento, devido à demanda de mercado. As pesquisas que focam a produção científica em contabilidade no Brasil têm crescido nos últimos anos, embora ainda de forma incipiente. 
Figura 1 - Produtividade ao longo dos anos.

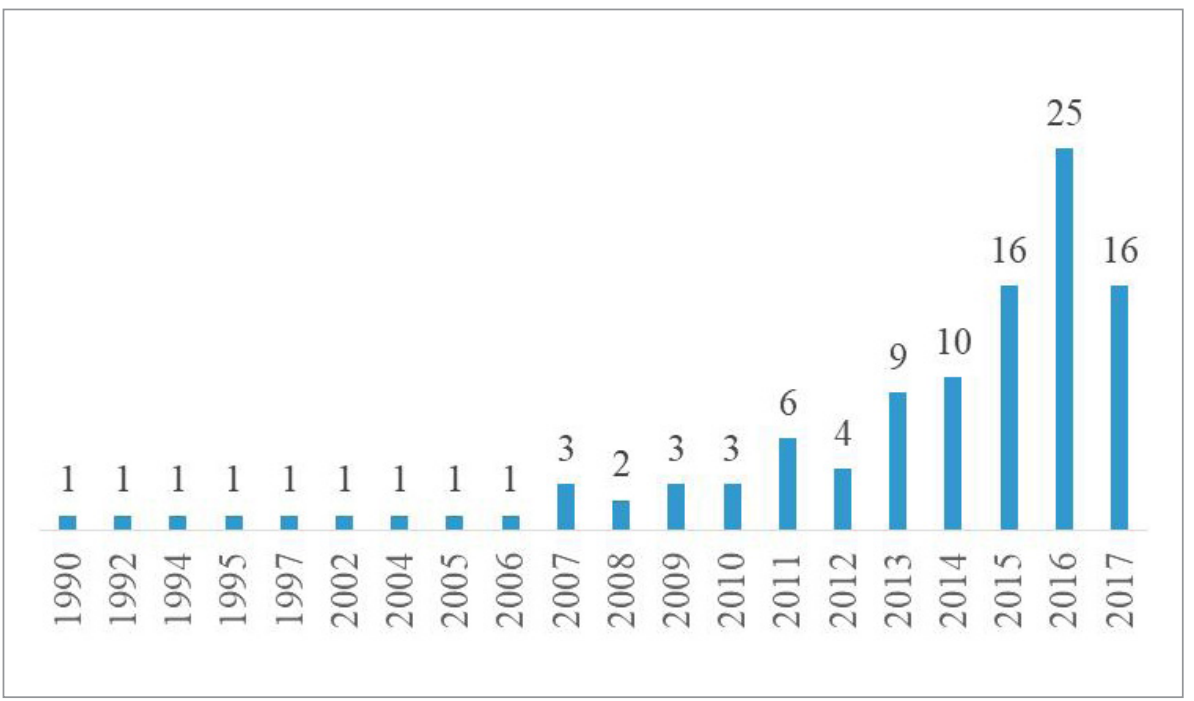

Fonte: Dados da pesquisa

A Figura 2 apresenta como se distribui a amostra de acordo com seu tipo de documento. A maior parte dos trabalhos publicados na área de interesse deste estudo $(78,3 \%)$ foram publicados como artigo científico, e esse resultado corrobora a tendência internacional, visto que a maior parte da produção científica ao redor do mundo tem propagado o conhecimento através deste formato; em segundo lugar são os artigos de conferência $(18,8 \%)$, sugerindo-se que o assunto tem sido discutido em eventos de contabilidade; e por fim, capítulo de livros $(1,9 \%)$ e artigo empresarial com apenas uma observação.

Figura 2 - Tipos de documentos.

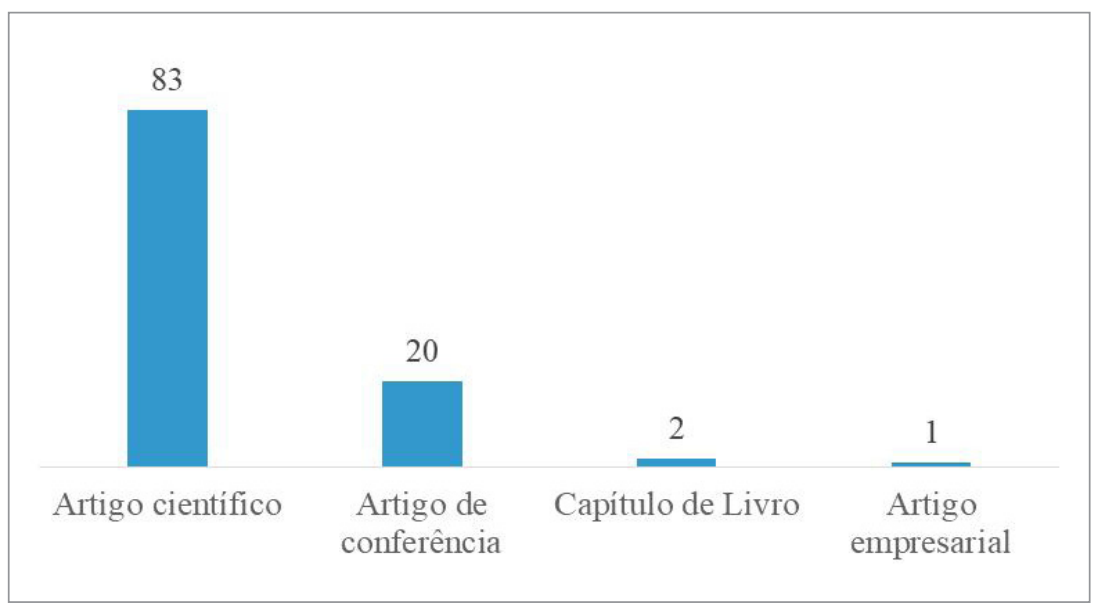

Fonte: Dados da pesquisa

A Figura 3 expõe as áreas temáticas nas quais de trabalhos produzidos nestas áreas. Para estão sendo produzidos os trabalhos coletados. realizar a distribuição de trabalhos por subárea, A nomenclatura apresentada foi realizada após realizou-se a análise de título e resumo de cada pesquisas pertinentes em plataformas teóricas documento coletado, a fim de otimizar a definição relacionadas, constatando-se o grande número e segregação. 
A subdivisão das áreas temáticas é feita através de pesquisas em plataformas teóricas similares, que já realizam divisões em áreas da contabilidade, bem como prévia análise no momento da coleta de documentos, dando antecipadamente margem à escolha de áreas pertinentes. Desse modo, as áreas: (1) contabilidade gerencial, remete ao tratamento das medidas de custeio, tema bastante estudado na interface agronegócio, fruticultura e setores correlatos; (2) reconhecimento e mensuração englobam estudos referentes à contabilização de ativos biológicos, tema de grande complexidade e recorrente em pesquisas da área; (3) regulamentação, traz consigo trabalhos correlatos a leis que tratam do agronegócio no Brasil e no mundo, bem como da adoção das normas internacionais (IFRS), que alteram o trato de determinadas áreas da contabilidade; (4) mercado financeiro e arbitragem tem intenção de abarcar estudos que tratam da abertura de capital, operações de crédito e financiamento e a transação de commodities no mercado financeiro internacional; (5) social disclosure, a divulgação transparente de premissas de tratamento contábil de qualquer que seja a área, é de extrema importância para produzir informações contábeis relevantes aos mais diversos usuários; (6) contabilidade socioambiental destaca os estudos relacionados à responsabilidade do agronegócio frente ao meio ambiente, haja vista que esta relação pode ser extremamente danosa.

Figura 3 - Subáreas temáticas.

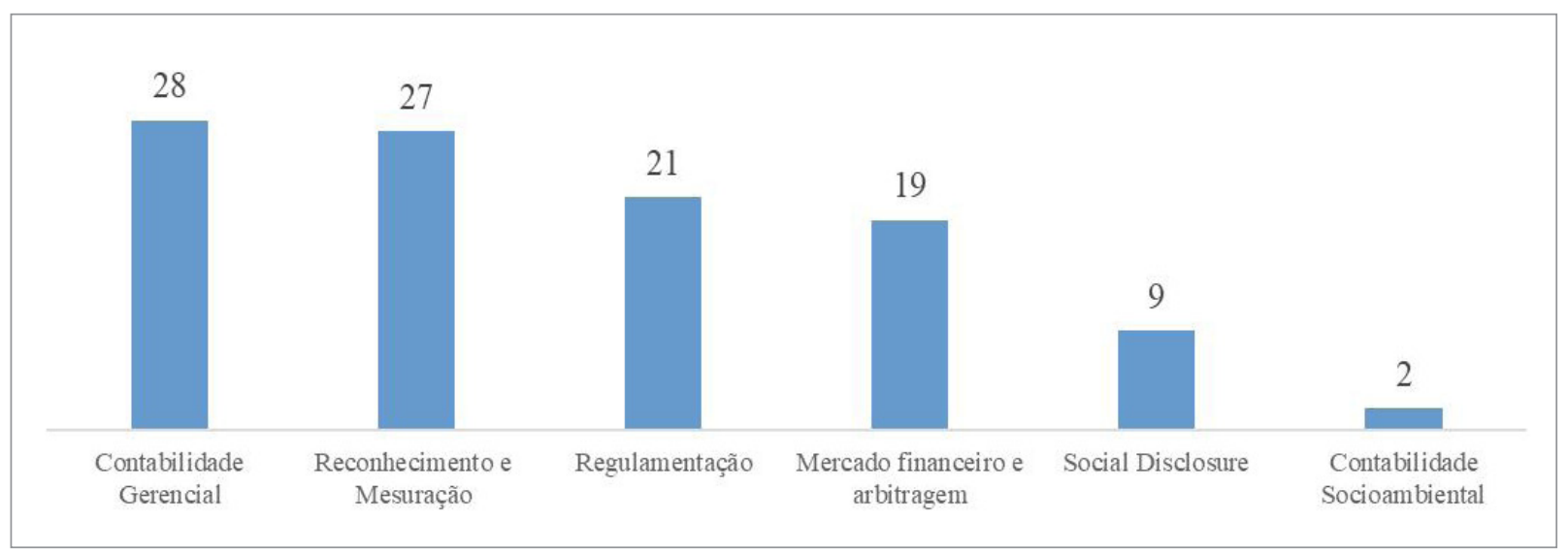

Fonte: Dados da pesquisa

A partir dos dados anteriormente apresentados, pode-se inferir que a produção científica de trabalhos nas áreas de contabilidade gerencial $(26 \%)$ e reconhecimento e mensuração (25\%) é significativa, com mais da metade dos trabalhos coletados nesta amostra, seguidos por regulamentação $(20 \%)$, mercado financeiro e arbitragem (18\%), social disclosure (9\%) e contabilidade socioambiental (2\%).

A maior produção científica relacionada à contabilidade gerencial e reconhecimento e mensuração justifica-se pela complexidade atrelada ao estudo dos custos no agronegócio e à mensuração e avaliação de ativos como ativos biológicos, principalmente estudos sobre valor justo, fortemente presentes neste segmento.

Pesquisas científicas na área de regulamentação se justificam pelo fato do setor ser regulado e amparado por leis (ex: Lei n ${ }^{\circ} 8.171 / 91$ ), as quais embasam tais estudos. Para Rech e Oliveira (2011), uma grande mudança causada pela adoção da IAS 41 é a determinação de que os efeitos das variações no valor justo dos ativos biológicos devem ser levados diretamente para as contas de resultado, o que impacta imediatamente a conta de lucros e perdas das empresas. 
Na Figura 4 é possível observar a evolução de ano a ano de cada uma das áreas temáticas estudadas. A partir de 2008, com a promulgação da Lei 11.683/2007, o Brasil passou a adotar as Normas Internacionais de Contabilidade, as International Financial Reporting Standards (IFRS), tornando-se obrigatória para todas as empresas de capital aberto e capital fechado e médio porte (ANTUNES et al., 2012).
A partir deste marco, observa-se um aumento e constância de publicação nas áreas de avaliação e mensuração e contabilidade gerencial, principalmente devido à adoção das normas internacionais de ativos biológicos, aquecendo o estudo acadêmico tanto para questões relativas ao custeio, quando sua mensuração. Em 2016, houve um pico de estudos em contabilidade gerencial no setor de agronegócios.

Figura 4 - Evolução das áreas temáticas.

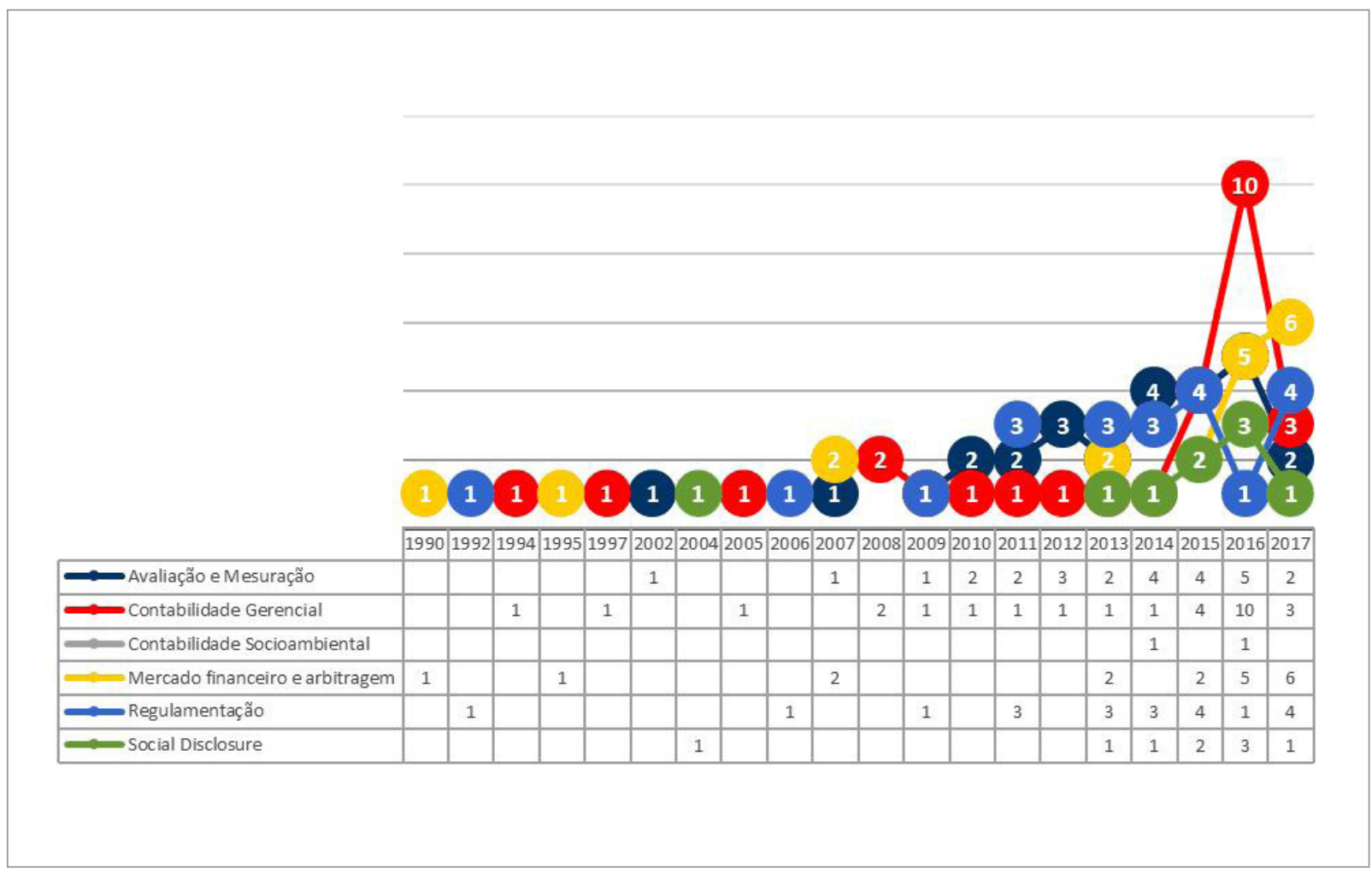

Fonte: Dados da pesquisa

Outro tema que ganhou certa relevância foi o de mercado financeiro e arbitragem, o que deve-se principalmente pelo uso de derivativos agropecuários. A prática do uso de objetos financeiros derivativos tem se consolidado recentemente no Brasil, inclusive como alternativa na comercialização de soja, que é o principal grão do agronegócio brasileiro. Novas pesquisas estão sendo produzidas principalmente para demonstrar o quão necessário se faz o uso de ferramentas que reduzam o risco, visto que se trata de um mercado muito competitivo (BORGES, 2016; MORAIS; CARNEIRO, 2017).

As fontes de origem dos trabalhos da amostra também foram analisadas (Tabela 2). A contagem de maior frequência de trabalhos publicados dentro da amostra foi no periódico Custos e Agronegócio On line; este é um periódico on-line e conta com classificação B1 na área de Administração Pública e de Empresas, Ciências Contábeis e Turismo no sistema QUALIS de classificação de periódicos científicos, quadriênio 2013-2016. O objetivo do 
periódico é publicação e disseminação de trabalhos científicos elaborados a partir da interface entre custos e agronegócio. Vinculada às bases Emerald e Scopus, a Agricultural Finance Review possui considerável frequência de publicação dentro desta amostra (7), seguida pela revista Agribusiness com a terceira maior frequência de publicação na área de interesse deste estudo (3).

Tabela 2 - Fontes de origem dos trabalhos.

\begin{tabular}{lcc}
\hline \multicolumn{1}{c}{ Fontes } & Frequência & $\mathbf{\%}$ \\
\hline Custos e Agronegócio On line & 13 & $12,25 \%$ \\
Agricultural Finance Review & 7 & $6,6 \%$ \\
Agribusiness & 3 & $2,8 \%$ \\
Agricultural Economics Zemedelska Ekonomika & 3 & $2,8 \%$ \\
Economic Science for rural development production and taxes & 3 & $2,8 \%$ \\
Revista de Economia e Sociologia Rural & 3 & $2,8 \%$ \\
\hline
\end{tabular}

Fonte: Dados da pesquisa

Em relação a se quantificar os países nos quais se localizam as instituições de ensino superior que afiliam todos os autores da amostra, utilizando-se da contagem completa, é possível traçar um panorama global que indica os países ou as regiões do mundo mais prolíficas no que se refere à produção científica analisada neste trabalho.

Figura 5 - Nacionalidade das instituições com quatro ou mais autores.

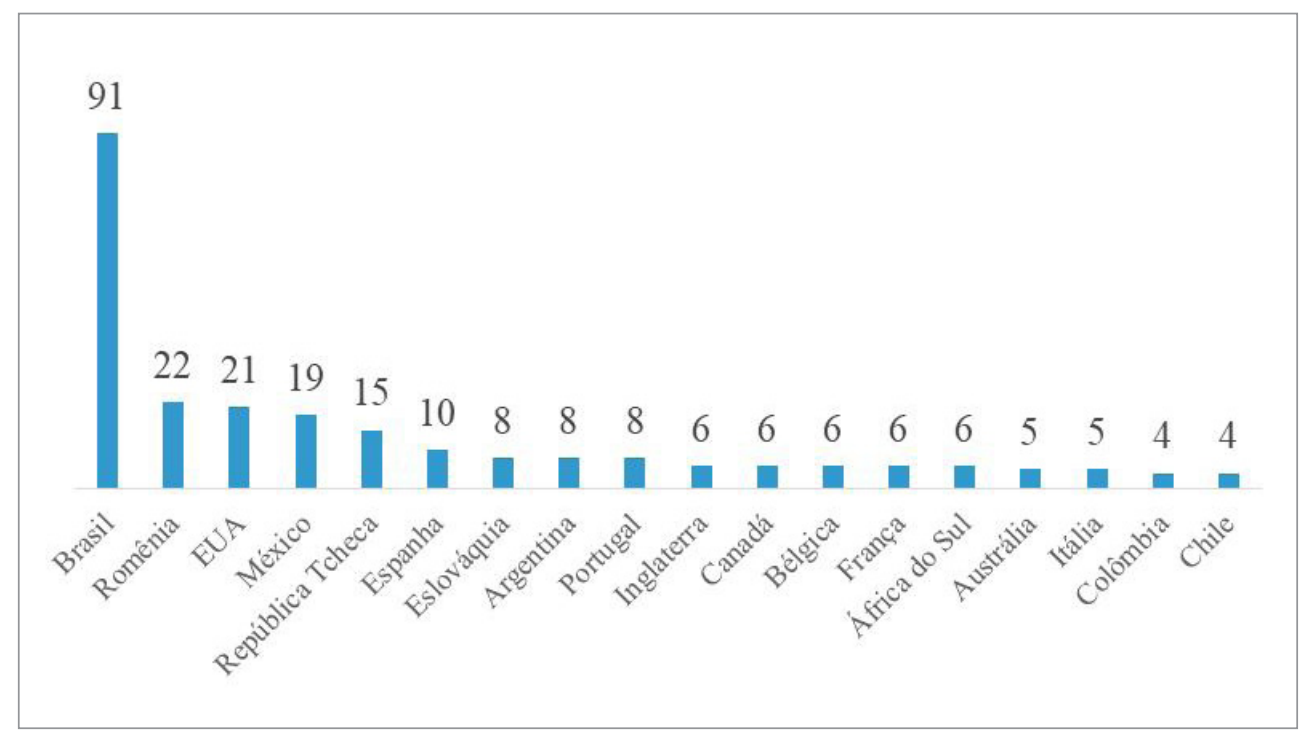

Fonte: Dados da pesquisa

O país com mais contribuições é o Brasil, detentor de um total de 91 (31,8\%), seguido por Romênia e Estados Unidos, possuidores, respectivamente, de $22(7,7 \%)$ e $21 \quad(7,3 \%)$ pesquisas. Por ser caracterizado, de acordo com Pereira e Moura (2016), por um setor de agronegócios de alto impacto na economia, é natural que o Brasil possua destaque quantitativo no número de trabalhos científicos sobre contabilidade atrelada ao agronegócio, o que também se reflete na liderança em publicações do gênero observada na revista brasileira Custos e Agronegócio On line. 
Impulsionada pelas publicações brasileiras e estadunidenses, além de contar com as boas colocações de México, Argentina, Canadá, Colômbia e Chile, a América desponta como o continente com mais contribuições, responsável por $55 \%$ da produção. Em segundo lugar se encontra a Europa, cujos destaques são a Romênia com 22 contribuições (7,7\%), a República Tcheca com 15 (5,2\%), a Espanha com 10 (3,5\%), a Eslováquia com $8(2,8 \%)$ e Portugal também com 8 (2,8\%), somando um total de 63 participações $(36,5 \%)$. Nos outros continentes a contribuição é bem mais baixa, sendo a África responsável por 9 (3,2\%), a Ásia por $8(2,8 \%)$ e a Oceania por 7 (2,5\%).

Os autores mais prolíficos constatados nesta pesquisa, aqueles com ao menos três produções, são: Carlos Omar Trejo-Pech, Hana Bohusova, Josep M. Argilés e Lisa Jack; para eles, foram analisadas todas as referências bibliográficas de cada um dos 12 artigos por eles produzidos. Com o auxílio de ferramentas do Portal de Periódicos da CAPES e do Microsoft Office Excel ${ }^{\circledR}$, tem-se um total de 480 citações.

Ao analisar as referências bibliográficas coletadas, tem-se a informação de que os autores mais citados pelos autores aqui presentes são: Mary E. Barth, citada 14 vezes e Josep Maria Argilés, citado 7 vezes. Um fator interessante é que o segundo autor mais citado dentre os principais autores, Josep Argilés, é um dos principais autores da amostra coletada. Outro ponto é que mesmo o Brasil sendo o país com maior produção na área, não existem brasileiros entre os principais autores desta amostra; isto pode ser justificado pelo fato de muitos autores brasileiros contarem com apenas uma contribuição em trabalhos na área e que alguns trabalhos publicados não constarem palavras-chave em inglês, as quais foram utilizadas neste estudo.

\section{Análise pela Lei de Lotka}

Nesta seção serão apresentadas as análises da produtividade dos autores a partir da contagem direta, completa e fracionada, além da verificação sobre a hipótese levantada pela pesquisa da adequação ou não da Lei de Lotka. Encontra-se na Figura 6 a relação entre o número de autores e seu número de contribuições. A contagem completa se destaca por possuir o maior número de autores com uma única contribuição, o que encontra explicação na natureza desta contagem, caracterizada por atribuir um peso igualitário e unitário para cada coautor. A segunda forma de contagem com mais contribuições unitárias é a direta, ficando a terceira posição para a contagem fracionada.

Figura 6 - Número de autores por contribuições e tipo de contagem.

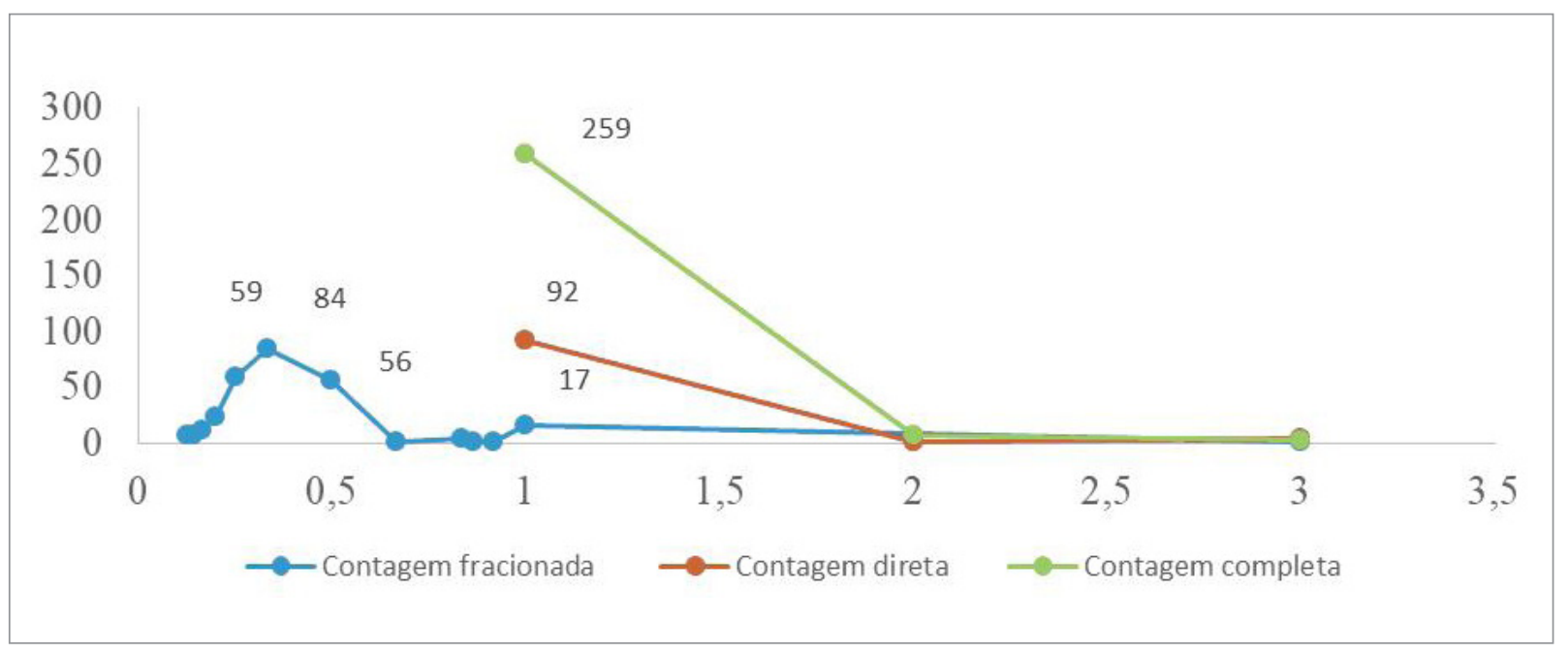

Fonte: Dados da pesquisa 
De acordo com os dados apresentados na Figura 6, que exibem umatendênciaà zerona medida em que o número de autores cresce em todos os tipos de contagem, muitos contribuintes publicam poucas vezes sobre contabilidade aplicada ao setor de agronegócio. As três contagens se aproximam entre 2 e 3 contribuições, o que vai ao encontro do trabalho de Urbizagastegui (2008) e fortalece a ideia de que poucos autores são responsáveis por um maior número de contribuições. Observase na contagem fracionada um comportamento que se assemelha ao de uma parábola negativa com vértice próximo a 100 autores com menos de 0,5 contribuição, ou seja, boa parte dos trabalhos coletados são realizados em coautoria.

Especificamente sobre a avaliação de ajuste à Lei de Lotka, Pao (1985) propôs cinco passos para se testar a adequação de um grupo de autores à Lei. Nesse processo estão detalhados os métodos para o cálculo do expoente $n$, que foi considerado 2 por Lotka (1926), e da constante c, que representa a porcentagem de autores com apenas uma contribuição e foi calculada como 0,6079 por Lotka (1926). Os cinco passos são:

- Coleta dos dados e contagem direta dos autores;

- Organização dos dados em uma tabela com duas colunas referentes ao número de contribuições (x) seguidos pelo número de autores que contribuíram $\mathrm{x}$ vezes;

- Acrescentando-se as colunas $\mathrm{X}=\log \mathrm{x}$ e $\mathrm{Y}=\log \mathrm{y}$ à tabela, além das colunas $\mathrm{XY}$ e $\mathrm{X}^{2}$, é possível o cálculo do expoente $\mathrm{n}$, determinado como a inclinação da reta que melhor representa a série de dados, por meio do Método dos Mínimos Quadrados recomendado pela autora ao se substituir os valores na Equação 2.

$$
n=\frac{N \sum X Y-\sum X \sum Y}{N \sum X^{2}-\left(\sum X\right)^{2}}
$$

$O$ resultado encontrado para o conjunto de dados analisados foi $n=3,25$, diferente do $n=2$ calculado originalmente por Lotka (1926);

$$
c=\frac{1}{\sum_{1}^{P}-1 \frac{1}{x^{n}}+\frac{1}{(n-1)\left(P^{n-1}\right)}+\frac{1}{2 P^{n}}+\frac{n}{24(P-1)^{n+1}}}
$$

- Para o cálculo de c, utilizando-se a metodologia sugerida pela autora, o resultado encontrado foi 0,8626 , substituindo-se os valores das variáveis na Equação 3 e considerando-se $\mathrm{P}=20$ para minimizar o erro residual;

- O último passo da série proposta por Pao é o teste Kolmogorov-Smirnov (K-S), no qual é possível determinar se um conjunto de dados segue, ou não, a lei proposta por Lotka. Realizando-se todos os cálculos desta etapa, aceita-se a hipótese de que o conjunto de dados reunido se adequa à Lei de Lotka com 0,01 nível de significância. O teste se dá pela comparação do $\mathrm{D}_{\text {máx }}$, maior diferença entre os valores acumulados dos autores por número de contribuições e os valores acumulados da porcentagem de autores para cada número de contribuições, ao valor crítico, dependente do número de observações e do nível de significância.

Tabela 3 - Dados para o teste Kolmogorov-Smirnov.

\begin{tabular}{ccccccc}
\hline $\mathbf{x}$ & $\mathbf{y}$ & $\mathbf{y} / \sum \mathbf{y}$ & $\mathbf{y} / \sum \mathbf{y}$ acumulado & $\mathbf{c} / \mathbf{x}^{\mathbf{n}}$ & $\mathbf{c} / \mathbf{x}^{\mathbf{n}}$ acumulado & $\mathbf{D}_{\text {máx }}$ \\
\hline $\mathbf{1}$ & 92 & 0,948454 & 0,948454 & 0,862611 & 0,862611 & $\mathbf{0 , 0 8 5 8 4 3}$ \\
$\mathbf{2 2}$ & 1 & 0,010309 & 0,958763 & 0,090722 & 0,953332 & 0,005431 \\
$\mathbf{3 3}$ & 4 & 0,041237 & 1 & 0,024297 & 0,977629 & 0,022371 \\
Total & 97 & & & & & \\
\hline
\end{tabular}

Fonte: Autores 
Por se tratar de uma amostra pequena, resultante da grande especificidade da temática observada, o valor crítico do teste tende a ser muito alto, já que o cálculo do valor crítico do teste K-S com 0,01 de significância, utilizado por Pao em seu estudo, é dado por $1,63 /\left(\sum \mathrm{y}\right)^{1 / 2}$, ou seja, a posição do número de observações (y) na equação faz com que um número maior resulte em um valor crítico menor e que um número menor de observações desencadeie um valor crítico maior.

Como a conclusão do teste K-S se resume a aceitar a hipótese nula caso $\mathrm{D}_{\text {máx }}$ seja menor que o valor crítico, é natural que não se possa rejeitar a conformidade à Lei de Lotka com um número baixo de artigos no banco de dados analisado. Pao (1985) exibe exemplos em que a teoria de Lotka é confirmada e outros onde não há esta confirmação, logo, o ponto de seu trabalho não é a verificação desta lei bibliométrica, mas a constatação de que a mesma varia de caso em caso e estas variações algumas vezes são significativas a ponto de romper com o postulado de Lotka, bem como podem ser sutis e não possuírem a significância necessária para rejeitar a conformidade com a lei bibliométrica. Também existem amostras maiores, como a utilizada por Sobrino, Caldes e Guerrero (2008), que aceitam a hipótese de conformidade com a Lei de Lotka, o que pode sugerir que o impacto do tamanho da amostra não seja tão grande em estudos deste gênero.

\section{Considerações Finais}

O presente estudo teve como objetivo analisar o perfil da produção científica em contabilidade aplicada ao setor do agronegócio, à luz da Lei de Lotka. Utilizou-se de técnicas bibliométricas para descrever as características da produção em contabilidade aplicada ao setor de agronegócios, a partir de coleta de trabalhos publicados em cinco bases de dados multidisciplinares: Emerald, Scopus, Web of Science, SciELO e ScienceDirect. Um perfil sobre as publicações foi traçado, identificando que o quantitativo da produção científica na área tem crescido nos últimos 10 anos, com foco na discussão em contabilidade gerencial e tratamento para reconhecimento e mensuração. Estas subáreas têm encontrado espaço no setor estudado, principalmente pela discussão acerca dos ativos biológicos e custos no agronegócio.

Os periódicos identificados com o maior número de contribuições foram Custos $e$ Agronegócio On line (13), Agricultural Finance Review (7) e Agribusiness (3); a liderança por uma revista científica brasileira representa a importância que o País, de caráter exportador, tem frente ao setor de agronegócios, corroborando os achados desta pesquisa, na qual $31,8 \%$ dos autores possuem vínculo com instituições de ensino superior brasileiras. Entretanto, os mais prolíficos destacados não são brasileiros; o fato pode ser evidenciado por: (1) apesar da quantidade de produção, não são muitos autores brasileiros que publicam várias vezes no tema; ou (2) poucos pesquisadores brasileiros publicam em inglês, logo, as palavras-chave elencadas por esta pesquisa não retornaram como resultado.

Sobre a produtividade dos autores, a máxima de Lotka (1926) pôde ser observada, pois a produção tem sido muito dispersa, com muitos autores produzindo pouco e poucos produzindo muito, constatação comum quando observada em outras áreas do conhecimento. Entretanto, quando analisado o método empírico de ajustamento ao inverso quadrado, proposto por Pao (1985), os coeficientes que representam a relação de produtividade dos autores se distanciou da Lei de Lotka, o $\mathrm{n}$ inicialmente constatado como 2 foi encontrado em 3,25 e o c, número que representa a porcentagem de autores com 1 contribuição, ao invés de 0,6079 a relação aumentou para 0,8626.

A relação estatística foi verificada através do teste Kolmogorov-Smirnov (K-S), os resultados desta pesquisa apontam a não rejeição da hipótese nula a 0,01 nível de significância. Para aceitação da hipótese alternativa, o $\mathrm{D}_{\text {máx }}$ deveria ser menor que o valor crítico, porém, a especificidade da temática com a presença de poucos artigos observados na área impossibilitou o aumento do valor crítico. 
Grande parte dos estudos bibliométricos não destaca a utilização de um teste estatístico que comprove a aderência do conjunto de dados observado à Lei de Lotka, ao contrário deste trabalho, que se vale da metodologia de Kolmogorov-Smirnov para este fim. Contudo, o número reduzido de dados coletados é um fator limitador para o teste, que carece de um número maior de documentos, sendo uma das limitações da pesquisa.

Finalmente, algumas sugestões para pesquisas futuras são o acréscimo de outras bases de dados; a inclusão de palavras-chave em outros idiomas, diferentes dos da língua inglesa; além da inserção de pesquisas em eventos científicos internacionais sobre o tema.

\section{Referências}

ANTUNES, M. T. P.; GRECCO, M. C. P.; FORMIGONI, H.; NETO, O. R. M., A adoção no Brasil das normas internacionais de contabilidade IFRS: o processo e seus impactos na qualidade da informação contábil. Revista de Economia e Relações Internacionais, São Paulo, v. 10, n. 20, p. 5-19, 2012.

ARAÚJO, C. A. Bibliometria: evolução histórica e questões atuais. Em Questão, Porto Alegre, v. 12, n. 1, p. 11-32, 2006.

ARAÚJO, R. F.; ALVARENGA, L. A bibliometria na pesquisa científica da pós-graduação brasileira de 1987 a 2007. Encontros Bibli: Revista Eletrônica de Biblioteconomia e Ciência da Informação, Florianópolis, v. 16, n. 31, p. 51-70, 2011.

BORGES, L. T. Uso do hedge como proteção à variação do preço do dólar e da soja pela COAMO agroindustrial cooperativa. $2016.60 \mathrm{f}$. Trabalho de Conclusão de Curso (Especialização em Gestão do Agronegócio) - Universidade Federal do Paraná, Curitiba, 2016.

BOURDIEU, P. O campo científico. In: ORTIZ, R. (org.). Pierre Bourdieu: sociologia. São Paulo: Ática, 1983. p. 122-155.
CAFÉ, A.; CARVALHO, K.; MENEZES, V.; ODDONE, N. A elite acadêmica da sociologia no Brasil e sua produção científica. Informação \& Informação, Londrina, v. 16, n. 3, p. 19-39, 2011.

DANIELSON, M. G; HECK, J. L. Giving Credit where credit is due: summary analysis of the most prolific authors in 15 high-impact accounting journals. Advances in Accounting, Albany, v. 26, n. 2, p. 195-206, 2010.

FIGUEIREDO, A. M.; SANTOS, M. L.; LIMA, J. F. Importância do agronegócio para o crescimento econômico de Brasil e Estados Unidos. Gestão \& Regionalidade, São Caetano do Sul, v. 28, n. 82, p. 5-17, 2012.

GASQUES, J. G.; REZENDE, G. C. de; VERDE, C. M. V.; SALERMO, M. S.; COCEIÇÃO, J. C. P. R. da; CARVALHO, J. C. de S. Desempenho e crescimento do agronegócio no Brasil. Brasília: IPEA, 2004. Disponível em: https://bit.ly/3feo1yP. Acesso em: 15 jan. 2019.

GOODMAN, L. A. Kolmogorov-Simonov tests for psychological research. Psychological Bulletin, Washington, v. 51, n. 2, p. 160-168, 1954.

GUEDES, V. L. S.; BORSCHIVER, S. Bibliometria: uma ferramenta estatística para a gestão da informação e do conhecimento, em sistemas de informação, de comunicação e de avaliação científica e tecnológica. In: ENCONTRO NACIONAL DE CIÊNCIA DA INFORMAÇÃO - CINFORM, 6., Salvador. Anais [...]. Salvador: UFBA, 2005. Disponível em: https://bit.ly/2W3zWI5. Acesso em: 15 jan. 2019.

JANK, M. S.; NASSAR, A. M.; TACHINARDI, M. H. Agronegócio e comércio exterior brasileiro. Revista USP, São Paulo, n. 64, p. 14-27, 2005.

LEITE FILHO, G. A. Padrões de produtividade de autores em periódicos e congressos na área de contabilidade no Brasil: um estudo bibliométrico. Revista de Administração Contemporânea, Rio de Janeiro, v. 12, n. 2, p. 533-554, 2008.

LOTKA, A. J. The frequency distribution of scientific productivity. Journal of the Washington Academy of Sciences, Washington, v. 16, n. 12, p. 317-323, 1926. 
MERIGÓ, J. M.; YANG, J. B. Accounting research: a bibliometric analysis. Australian Accounting Review, Hoboken, v. 27, n. 80, p. 71-100, 2017.

MORAIS, L. C.; CARNEIRO, L. F. R. Uso de derivativos agropecuários como alternativa na comercialização da soja no mato grosso do sul. In: ENCONTRO INTERNACIONAL DE GESTÃO, DESENVOLVIMENTO E INOVAÇÃO, 2017, Naviraí, MS. Anais [...]. Naviraí: UFMS, 2017. Disponível em: https://bit.ly/3e9brzn. Acesso em 15 de janeiro de 2019.

PAO, M. L. Lotka's law: a testing procedure. Information Processing \& Management, Elmsford, v. 21, n. 4, p. 305-320, 1985.

PEREIRA, N. A; MOURA, M. F. Custos no agronegócio: um estudo bibliométrico dos anos de 2003 a 2013. RAGC: Revista de Auditoria, Governança e Contabilidade, Monte Carmelo, v. 4, n. 10, p. 134-149, 2016.

QUESADA, V. B.; MINGUILlO, D.; CHINCHILLA, Z. R.; ANEGÓN, F. M. Structure of Spanish scientific collaboration in Library and Information Sciences (Scopus 1999-2007). Revista Interamericana de Bibliotecología, Medellín, v. 33, n. 1, p. 105-123, 2010.

RECH, I. J.; OLIVEIRA, K. G. Análise da aplicação do CPC 29 e IAS 41 aos ativos biológicos no setor de silvicultura. In: CONGRESSO ANPCONT, 5., 2011, Vitória, ES. Vitória: ANPCONT, 2011. p. 1-16.

RIBEIRO, H. C. M; SILVA, M. C. Mapeando a produção acadêmica da revista ambiente contábil à luz da bibliometria e rede social de 2009 a 2014. Sinergia, Rio Grande, RS, v. 20, n. 2, p. 89-102, 2016.

SILVA, N. M. G.; CESÁRIO A. V.; CAVALCANTI I. R. Relevância do agronegócio para economia brasileira atual. In: ENCONTRO DE INICIAÇÃO À DOCÊNCIA, 2006, 10., João Pessoa, PB. Anais [...]. João Pessoa, UFPB, 2006. Disponível em: https://bit.ly/2ZRE0MJ. Acesso em: 15 jan. 2019.

SOBRINO, M. I. M.; CALDES, A. I. P.; GUERRERO, A. P. Lei de Lotka Aplicada à produção científica da área de ciência da informação. Brazilian Journal of Information Science, v. 2, n. 1, p. 16-32, 2008.
SOUZA, F. J. V; BARROS, C. C.; ARAÚJO, A. O.; SILVA, M. C. Perfil dos artigos sobre agronegócios publicados nos periódicos de contabilidade com estratos CAPES. ConTexto, Porto Alegre, v. 12, n. 22, p. 87-102, 2012.

TEIXEIRA, E. B. A análise de dados na pesquisa científica: importância e desafios em estudos organizacionais. Desenvolvimento Em Questão, Ijuí, v. 1, n. 2, p. 177-201, 2003.

UNIVERSIDADE DE SÃO PAULO - USP. Escola Superior de Agricultura Luiz de Queiroz - ESALQ. Centro de Estudos Avançados em Economia Aplicada - CEPEA. PIB do agronegócio brasileiro de 1996 a 2018. Piracicaba, SP: USP/CEPEA/ ESALQ, 2018. Disponível em: https://www.cepea. esalq.usp.br/br/pib-do-agronegocio-brasileiro. aspx. Acesso em; 11 jul. 2019.

URBIZAGASTEGUI, R. A produtividade dos autores sobre a Lei de Lotka. Ciência da Informação, Brasília, v. 37, n. 2, p. 87-102, 2008.

VANTI, N. A. P. Da bibliometria à webometria: uma exploração conceitual dos mecanismos utilizados para medir o registro da informação e a difusão do conhecimento. Ciência da Informação, Brasília, v. 31, n. 2, p. 369-379, 2002.
Recebido em: 21 fev. 2020

Aceito em: 22 maio 2020 
Benigno, G. O. L. et al. 